\title{
RETAZOS CHIAPANECOS DE CULTURA
}

\author{
Fragments of Chiapaneco Culture
}

\author{
Diana Guillén*
}

DOI: http://dx.doi.org/10.29043/liminar.vl8il.718

Reseña de Antología del ensayo moderno en Chiapas: esbozo de una historia cultural. Selección y prólogo de Ignacio RuízPérez. Tuxtla Gutiérrez, Chiapas: CONECULTA, 2018.

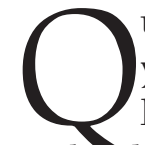

uienes provenimos de disciplinas sociales y humanísticas distintas, que no ajenas, a la historia, encontramos en esta última un núcleoturo con propiedades estructurantes. Se trata de algo similar a lo que sucede con las matemáticas en el terreno de las llamadas ciencias exactas; sin la base de la que proveen a otros campos del conocimiento, estos no se hubiesen podido desarrollar. En nuestro caso, la diacronía ayuda a recuperar el dinamismo de los procesos societales, atributo que por momentos se pierde cuando su esencia se abstrae en conceptos y teorías.

Al contacto con la historia el análisis sobre los múltiples rostros que asumen las sociedades contemporáneas se enriquece. Esta "verdad de Perogrullo" es útil para insistir en que nuestro presente conjuga los tiempos ya idos y los que están por venir. Bajo tal presunción, el recorrido que propone Ignacio Ruiz Pérez para el entramado cultural chiapaneco resulta sugerente y a la vez provocador.

Utilizo ambos adjetivos de manera deliberada. $\mathrm{La}(\mathrm{re})$ lectura de materiales cuyos hilos conductores se entretejen para mostrar miradas disímiles y al mismo tiempo complementarias de la cultura local, abre la puerta para asomarse, así sea fugazmente, al pensamiento de personajes que en algún alto en el camino durante las últimas tres centurias han participado del devenir de la entidad chiapaneca. La travesía se vive de manera individual dependiendo del conocimiento que se tenga sobre los temas abordados y de la existencia de empatías o lejanías respecto a las plumas que, en veintinueve entregas, nos acercan a ellos. Pero poco importa la manera como cada cual se apropie de los textos en cuestión; al concluir su recorrido el viajero confirmará la policromía que ha caracterizado las visiones de los chiapanecos, por nacimiento o por adopción, sobre sí mismos y sobre los demás.

Trasladarse a épocas ya idas de la mano de un religioso y literato que llegó al mundo en Tapachula cuando esta formaba parte del Reino de Guatemala; acercarse al pensamiento de intelectuales cargados de erudición decimonónica; o bien hurgar en algunas de las piezas que en la academia y el arte se han

Enviado a dictamen: 31 de septiembre de 2019. Aprobación: 2 de diciembre de 2019. 
producido a lo largo de los siglos XX y XXI, da cuenta de riquezas culturales que desafían al positivismo historiográfico.

Es bien sabido que el 1ํㅡe enero de 1994 Chiapas acaparó primeras planas nacionales e internacionales $y$, en medio del azoro que produjo la irrupción en la arena pública del Ejército Zapatista de Liberación Nacional (EZLN), se multiplicaron los esfuerzos por dar cuenta de lo sucedido. De pronto, se fuese o no experto en la materia, se identificaron causalidades de corto, mediano y largo plazo y creció el interés por la entidad más allá de la belleza física que le daba fama y del folclore que atraía a visitantes de todo tipo.

Tanto para el turismo proveniente de otras partes de la República o del extranjero, como para los estudiosos de la naturaleza y la sociedad, esta región del sureste mexicano había representado desde hacía tiempo un poderoso imán, pero el surgimiento del EZLN potenció su fuerza como lugar de encuentro/ desencuentro entre las civilizaciones indígena y occidental. Tras los escenarios sincréticos que en ese momento llamaban la atención, se conjugaban procesos que a lo largo de los siglos habían generado relaciones desiguales y poco equitativas.

Junto con las uvas que despedían el año viejo, se levantó la voz para exigir nuevos horizontes. Se apeló para ello a las armas y se declaró una guerra cuya bandera tenía en buena medida que ver con las desventajas construidas socialmente alrededor de pertenencias étnicas, incluso si al ondearla se iba más allá de estas últimas. El tema de fondo eran una pobreza y un abandono que contrastaban con la explotación de las riquezas que Chiapas poseía. Tanto su incorporación al pacto federal en condiciones poco ventajosas, como el tipo de intercambios que se habían establecido internamente, se traducían en altas dosis de marginación para buena parte de sus pobladores.

Un lustro antes Thomas Benjamin había utilizado esa paradoja para titular su análisis sobre las razones por las que la entidad había avanzado en tal dirección: A Rich Land, a Poor People: Politics and Society in Modern Chiapas, o Chiapas. Tierra rica, pueblopobre. Historia política y social, como se tradujo al español. El desafío que en
1994 lanzó el EZLN al Estado mexicano se enmarcó en esa realidad de contrastes, pero la precariedad que padecían sus milicianos y bases de apoyo pasaba por encuentros/desencuentros inscritos en un terreno que, más temprano que tarde, se convirtió en un referente entreverado con las demandas zapatistas: el de la cultura.

Antonio García de León, al igual que Benjamin, reconstruyó la larga duración partiendo de hilos conductores a los que la esfera de la cultura era transversal. Su Resistencia y utopía: memorial de agravios y crónicas de revueltas y profecías acaecidas en la provincia de Chiapas durante los últimos quinientos años de su historia, editada por primera vez en 1985, es otra de las historias que suele consultarse cuando se buscan análisis panorámicos sobre Chiapas. Si bien dicha obra no se circunscribe al ámbito de las ideas, el papel de lo inmaterial se hace presente a lo largo de ella, mostrando cómo las relaciones de clase se cimentaron entremezcladas con factores culturales provenientes de entornos diferenciados.

Ambos ejemplos, elegidos por tratarse de reconstrucciones históricas de carácter general, me llevan a suscribir la pertinencia académica de proponer una sistematización de aspectos de la cultura que a primera vista parecerían coto del ambiente artístico. Coincido con Ruiz Pérez en que las manifestaciones de orden estético y los documentos que dan cuenta de ellas deben recuperarse como insumos valiosos para entender los procesos societales que en 1994 cobijaron un levantamiento armado. Ayudan a la comprensión de lo sucedido ese y los años posteriores, incluidos el diseño y puesta en marcha de institucionalidades paralelas con las que en ciertas zonas el EZLN mantiene vivo su reto al Estado mexicano.

Antología del ensayo moderno en Chiapas. Esbozo de una historia cultural resulta sugerente para acercarse a las múltiples aristas que están en la base del rostro heterogéneo y multiforme de la entidad y de los vestigios y elementos vivos de la cultura que a lo largo del tiempo se han acumulado en ella. Su factura, como la de toda buena obra, está salpicada por interpretaciones propias de lo que significan para la historia local 
descripciones, piezas literarias o estudios de corte tan variado que, a primera vista, no parecerían formar parte de un mismo rompecabezas.

Y sin embargo la apuesta es armar este último colocando cada una de sus partes en el orden cronológico en el que nacieron quienes los escribieron: "Utilidades de que todos los indios y ladinos se vistan y calcen a la española, y medios para conseguirlo sin violencia, coacción, ni mandato"; "Descripción geográfica del Departamento de Chiapas"; "Necesidad de una historia general de México"; "Un fraile prócer y una fábula poema (Estudio acerca de fray Matías de Córdova"; "La literatura chiapaneca (datos para su historia)"; "La poesía negra en México"; "Antología de poetas jóvenes: notas preliminares"; "San Sebastián desnudo en la feria de Chiapa de Corzo"; "Musil y el amor como vía de acceso a la autenticidad"; "El encuentro de los mayas de Chiapas con la Teología de la Liberación"; "El exilio guatemalteco en Chiapas"; "La marimba centroamericana no vino de África"; "Poemurales: un acto ético de la Liberación"; "Historia de dos abuelos y Jaime Sabines"; "Fronteras y colonialismo: una reflexión desde la frontera MéxicoGuatemala"; "Literaturas en diálogo sobre migraciones y fronteras”; “¿Guerra de castas según quién?: indios y ladinos en los sucesos de 1869"; "Trasgresión y alquimia"; "Los usos y costumbres en contra de la autonomía"; "El joven de Salvador Novo y otros relatos urbanos"; "Evocación de Eraclio Zepeda"; "El exilio y lo perdido: la poesía de Rosario Castellanos"; "Fiel imagen"; "Los libros y su sombra"; "Vegetalidad en la poesía de Eduardo Lizalde: fitonimias, fitofilias y fitofobias a partir de una lectura otra del Manual de flora fantástica"; "Apártate de la luz: el cinismo en la poesía de José Vicente Anaya”; "Las huellas de Carlos Fuentes en Francia a través de La Quinzaine Littéraire"; "El telar: el proceso creativo de tres poetas de Chiapas"; "Análisis de las entidades y conceptos femeninos como aprehensión del mundo".

Atrás de la elección/organización del material compilado hay una propuesta epistemológica encaminada a revisar "las distintas maneras en las que intelectuales, científicos sociales y escritores del estado o afincados en él han imaginado no sólo Chiapas y sus problemas sociales, políticos y culturales, sino también los diversos temas que conectan la realidad local con la transnacional". Mujeres y hombres con perfiles variopintos se reúnen así bajo un mismo paraguas, y guiados por Ruiz Pérez comparten retazos de su sentir y pensar: Fray Matías de Córdova y Ordóñez (17661828), Emeterio Pineda (1798-1850), Manuel Larráinzar (1809-1884), Flavio Guillén (1871-1933), Jesús Agripino Gutiérrez (1914-1977), Armando Duvalier (1914-1989), Eliseo Mellanes Castellanos (1916-2015), Mariano Penagos (1919-2009), Rosario Castellanos (1925-1974), Jan de Vos (1936-2011), Eraclio Zepeda (1937-2015), Roberto López Moreno (1942), Elva Macías (1944), Andrés Fábregas Puig (1945), Jesús Morales Bermúdez (1947), Jan Rus (1948), Óscar Wong (1948), Juan Pedro Viqueira (1954), José Martínez Torres (1955), Roberto Rico (1960), Gustavo Ruiz Pascacio (1963), Carlos Gutiérrez Alfonzo (1964), Luis Arturo Guichard (1973), Balam Rodrigo (1974), Víctor García Vázquez (1975), Karla Elisa Morales Vargas (1979), Matza Maranto Zepeda (1985), Viridiana Chanona (1985).

Frente al resultado de este tipo de esfuerzos editoriales, es importante recordar que cada uno de los autores y textos incluidos refleja por igual la decisión de priorizar ciertas temáticas y la postura del compilador respecto a ellas. No es que existiesen rutas predeterminadas, los ensayos que seleccionó Ruiz Pérez dan cuenta de búsquedas concienzudas fomentadas por una formación enciclopédica poco común en los tiempos que corren, y que se materializan en la propuesta de un amplio muestrario de representaciones de la cultura chiapaneca.

La concepción del género ensayístico que desarrolla se nutre de autores tan diversos como Alfonso Reyes, Gilbert Keith Chesterton, Luigi Amara, Michel de Montaigne, Malva Flores y Liliana Weinberg, y queda sintetizada de la siguiente manera: "Pero lo que me interesa resaltar aquí, y que quizá define mejor la índole del ensayo en América Latina, es lo que antes he llamado su condición liminal: la extraordinaria capacidad para negociar significados y formas, y para comunicar la experiencia humana". 
A partir de ese sentido libertario y flexible con el que identifica al género, se emparentan figuras literarias que, atendiendo a otras clasificaciones, no necesariamente compartirían códigos genéticos. El ensayo que a manera de prólogo abre la Antología hace las veces de brújula orientadora para descifrar los motivos que llevan a considerar por qué descripciones geográficas, historias escritas en pasado o en presente, estudios de corte antropológico, análisis poéticos, evocaciones y relatos personales constituyen una muestra representativa del heterogéneo universo de la cultura chiapaneca.

A mi juicio, la laxitud con la que quedan moldeados los contornos de lo que se entiende por ensayo termina por restarle utilidad al concepto, pues prácticamente cualquier escrito cabe en él. De igual manera me parece que podría profundizarse en la definición de historia cultural y no comparto la elección de algunos de los textos con los que, en progresión cronológica, se reconstruye el mundo chiapaneco de las ideas. Sin embargo, conviene enfatizar que tales objeciones están lejos de restar riqueza pedagógica a la titánica empresa que se propuso Ruiz Pérez; por el contrario, es de celebrarse que la haya llevado a buen término y que a través de su lente un público amplio tenga acceso a materiales que de manera individual le sería más difícil consultar.

Tratándose de una antología que hace honor al género, las distancias que cada lector establezca con la elección/organización de los fragmentos que le dan vida va de la mano con el reconocimiento de los aportes a la divulgación del conocimiento humanístico de la obra en su conjunto. Su solidez y consistencia tampoco deben ponerse en duda por diferencias entre los enfoques de quien la diseñó y de quienes nos convertimos en sus destinatarios.

Probablemente después de revisar Antología delensayo moderno en Chiapas. Esbozo de una historia cultural, más de un curioso por las aristas que se desprenden de ella caerá en la tentación de pensar: "no estoy de acuerdo con tal o cual cosa, yo hubiese...”. Las compilaciones históricas de carácter panorámico propician este tipo de diálogos imaginarios $y$, aun cuando establecerlos sea un mero juego del intelecto, al abrirlos se enriquece la lectura.
Yo, por ejemplo, me hubiese limitado a incursionar en el campo literario desde su acepción artística.

Esta parte es desde mi punto de vista la que tiene mayor presencia. La intención, en sí misma valiosa, de recuperar otras dimensiones de la cultura que remiten a encuentros/desencuentros civilizatorios de carácter estructural, se siente por momentos como un paréntesis más que como un eje con el mismo peso que se le da a la narración poética o ensayística, entendiendo la segunda en clave literario-artística.

Los textos sobre la guerra de castas o sobre la complejidad que envuelve las demandas en pro de la autonomía indígena son de primera. Lo mismo sucede con el análisis sobre el papel jugado por la teología de la liberación en la reproducción de la identidad étnica o sobre las distintas dimensiones que intervienen en el trazado de una línea fronteriza como la que separa México de Guatemala. Su valía y la importancia de promover su divulgación más allá de ambientes académicos en los que ya cuentan con reconocimiento, justifican su inclusión, pero surge la duda de hasta dónde son coherentes con el resto del material.

En el mismo sentido, voltear la mirada hacia autores clásicos de la historiografía chiapaneca e incorporar una geografía de la entidad pionera en su ramo o un llamado a la construcción de la historia nacional mexicana parecería una decisión acertada por la contribución que a través de ella hace la Antología a la difusión documental, pero la inquietud respecto al tipo de criterios utilizados para definir qué debe y qué no considerarse cuando se da forma a un compendio que esboce la historia cultural de Chiapas, se confirma.

Los argumentos de Ignacio Ruiz Pérez a favor de la naturaleza maleable del ensayo y, por consecuencia, de su uso como paraguas para cobijar escritos de muy distinto tipo, son contundentes. Más que contrapuntearlos, me interesa poner sobre la mesa el debate metodológico al que invitan en tanto los conceptos clave de los que parte se estiran en demasía. Entender "la historia cultural (ya en sí misma amplia y de compleja definición) como las representaciones e interpretaciones culturales que hombres y mujeres han dado al mundo; de esta manera, dicha disciplina abarca 
la historia de los supuestos que subyacen en la vida diaria" tiene sustento, igual que lo tienen los contornos que establece para el género ensayístico. La cuestión es el horizonte de totalidad que en ambos casos se abre.

En el prólogo se fijan coordenadas para aclarar: "1) por qué esta recopilación de ensayos funciona como un recorrido por las diversas maneras de representar la historia y la cultura en y desde Chiapas; y 2) en qué sentido ese viaje que se propone es una historia de las diversas ideas que han ocupado a intelectuales, científicos sociales y escritores en la entidad desde fines del siglo XVIII hasta nuestros días". Ambas líneas se desarrollan con minuciosidad y las razones del camino elegido quedan claras, por lo que las respuestas que se adelantan a diálogos imaginarios como los aquí planteados refrendan el rigor de los criterios empleados, independientemente de que se compartan o de que mentalmente se diseñen formas alternas de antologar fuentes y temas tan variados.

Los retazos chiapanecos de cultura que Ruiz Pérez decidió acercar a una vasta mayoría de posibles interesados en el tema constituyen en lo individual muestras valiosas del quehacer académico-artístico de la entidad. Reunirlos en un volumen y plasmar en la introducción cómo y por qué los seleccionó son actos que aluden a un proceso creativo que, como aquí se ha insistido, deja buenos legados. Además del mérito que el armado de las piezas pueda tener, el rompecabezas resultante promueve reflexiones críticas como las también mencionadas. Bienvenidas una y otra forma de apropiarse de Antología del ensayo moderno en Chiapas. Esbozo de una historia cultural, al final del camino cada público se inventará lecturas propias de tan sugerente y provocadora obra. 